UCRL -53206

UCRL-53206

DE82 005606

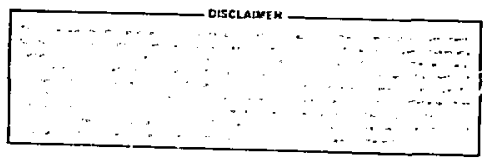

\title{
RTNS-II Targets: Cooling Channel Collapse Under Simulated Bonding Conditions
}

\author{
W. D. Ludemann \\ R. L. Brady \\ B. J. Schumacher
}

Manuscript date: April 2, 1981

\section{LAWRENCE LIVERMORE LABORATORY \\ University of California - Livermore, California - 94550}




\title{
RTNS-II Targets: Cooling Channel \\ Collapse Under Simulated \\ Bonding Conditions
}

\begin{abstract}
We experimentally determined the pressure limits that can be used to autoclavebond RTNS-Il targets without crushing the internal cooling channels. The maximum pressures are 40 to $55 \mathrm{MPa}\left(6\right.$ to $8 \mathrm{ksi}$ ) in the $300-10-450^{\circ} \mathrm{C}$ temperature regime.
\end{abstract}

\section{INTRODUCTION}

\section{Fabrication of RTNS-II Targets}

The RTNS-1! at LLNL produces an intense neutron flux that is used to soudy neutron damage in fus on-reactor materials. The larget assembly for the RTNS-II (Fig. 1) includes a target coated with tritium-loaded titanium. When a deuteion beam is directed on the target neutrons are produced by the reaction between deuterons and the tritium. Stopping the deuteron beam causes intense local heating of the target. This heat must be distributed and removed to keep the local temperature low so that tritium is not rapidly driven off. We distribute the heat by rotating the target at $5000 \mathrm{rpm}$, and remove the heat by circulating water through interna! channcls. We make targets of 23 - and $50-\mathrm{cm}$ (9- and 20-in.) diam. The larger targets are more highly stressed than the smaller at a fixed rotational velocity.

The targets are made as follows:

Target blanks are cut to the proper size from sheets of copper alloy, and channels are chemically etched into one of the faying surfaces. Target alloys used to date include Glidcop (copper dispersion-hastened with alumina), Amzirc (copper precipitation-hardened with zirconium), and MZC (copper precipitation-hardened ' with magnesium, zirconium, and chromium).

- Areas not to be bonded are masked with Mylar tape.

- Faying surfaces of Glidcop targets are electrolyticaliy coated with $13 \mu \mathrm{m}(0.5 \mathrm{mil})$ of copper and $6.4 \mu \mathrm{m}(0.25 \mathrm{mil})$ of gold: Amzirc and
MZC targets are couted with $2.5 \mu \mathrm{m}(0.1 \mathrm{mil})$ of copper and 0.4 , :m $(0.25$ mil) of gold.

- Three sets of targets are placed in a stainless sted bonding canister, each set separated hy a stainless steel spacer that helps give uniform pressure transmission and prevents the targets from sticking to each other.

- The canisters are evacuated and sealed with an electron beam weld. They are hol isostatically pressed under a pressure of 21 to 35 $\mathrm{MPa}\left(3\right.$ to $5 \mathrm{ksi}$ ) for $1 \mathrm{~h}$ at $510^{\circ} \mathrm{C}\left(95 \mathrm{C}^{\circ} \mathrm{fl}\right.$ fur $\mathrm{Cl}_{\mathrm{i}} \mathrm{l}$ cop targets, or at $400^{\circ} \mathrm{C}\left(750^{\circ} \mathrm{F}\right)$ for Amsiri and MZC targets.

- The bonded targets are removed from the canisters and pressure-tested to $3.5 \mathrm{MPa}$ (500 psi) for 23-cm-diam targets or to $17 \mathrm{MPa}(2500 \mathrm{psi}$ ) for 50-cm-diam targets.

- Targets that pass the pressure test are cold-formed into the required dish shape and again pressure-tested. The forming process may damage a bond sufficiently that a target will fail the second pressure test after having passed the first.

- Surviving targets are coated with titanium by physical vapor deposition, and the titanium is loaded with tritium at $400^{\circ} \mathrm{C}$.

\section{Target Failures During Proof Testing}

We report elsewhere ${ }^{1}$ on the difficulties in making 50-cm-diam targets able to survive the 17-MPa (2500-psi) proof test. The location of failures was either at the gold-gold interface, or in 


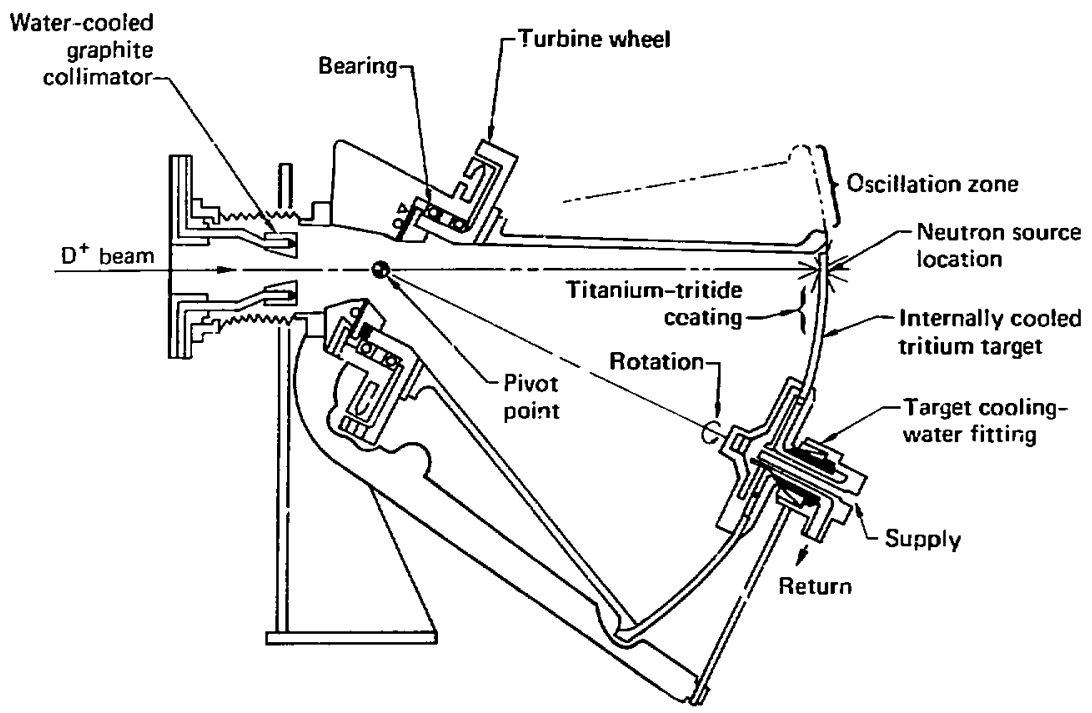

FIG. 1. Target assembly for the RTNS-Il. A deuteron beam is directed on the target (which is coated with tritium-loaded titanium), and the reaction between deuterons and the tritium produces neutrons. Because stopping the deuteron beam causes intense local heating, the target is rotated at about 5000 rpm to distribute the heat. Cooling water is circulated through tiny internal channels in the target to remove the heat.

the copper adjacent to the gold coating. Failure at the interface was the result of inadvertently bonding at too low a temperature. Failure in the copper was through voids that resulted from unequal amounts of gold and copper interdiffusion (Kirkendall effect). Reverse bending during hydroforming further damagea already weak bonds.

The time-at-temperature window between poor adhesion and an unacceptable amount of void formation was small. For that reason we examined the bonding process to look for a remedy.

\section{Fixing the Bonding Process}

The bonding parameters that we control are remperature, pressure, time at temperature and pressure, and interfacial barriers and bonding aids. The effects of these parameters on the bonding process are discussed in Ref. 1. We are in the process of determining the optimum parameters that will give good adhesion without an excessive amount of void formation

The purpose of this experiment was to limit the size of our test matrix by determining the maximum external load a target can withstand at a given temperature without an unacceptable amount of channel closure. We did this by cutting coupons from previously bonded targets, and loading them at various pressure-temperature combinations. We measured the deflection during creep, and sectioned the coupons to estimate the amount of channel closure. From these data ive estimated the upper limit of pressure that we can use for bonding. 


\section{TEST PROCEDURE}

We used 16- $\mu \mathrm{m}$ (5/8-in.) diam coupons cut from praviously bonded Glidcop 50-cm-diam targets. We tested them in compression, doing st:ess-s train tests on Amzirc and Glidcop coupons at ambient temperature, and constant load creep tests on Amzirc coupons at elevated temperatures.
In these tests we measured the deflections under load with three extensometers spaced $120^{\circ}$ apart. The reported deflections are the averages of these three measurements. We also cross-setioned the creep specimens and estimated the amount of channel closure from photomicrographs.

\section{RESULTS}

\section{Ambient Temperature Loading}

We loaded Amzirc and Glidcop disks at a rate of $1.3 \mathrm{~mm} / \mathrm{min}$ ( $0.050 \mathrm{in} . / \mathrm{min})$, and determined the stress at the proportional limit for each disk. The results for each specimen are presented in Tables 1 and 2. Here, flow stress refers to ratio of the applied load at the proportional limit to the total coupon area. The ac.ual stress in the lands is, of course, higher than the flow stress. As is shr wn in Fig. 2 . the etched channels in each target show three distinct areas from center to circumierence as the

TABLE 1. Flow stresses of Ainzirc coupons cul from a bonded 50 -cm-diam target.

\begin{tabular}{|c|c|c|c|c|c|}
\hline Position of coupon & $\begin{array}{l}\text { Solid area } \\
(\%)\end{array}$ & \multicolumn{2}{|c|}{$\begin{array}{l}\text { Flow stress across coupon } \\
\text { at proportional limit }\end{array}$} & \multicolumn{2}{|c|}{$\begin{array}{l}\text { Stress in lands at } \\
\text { peoportional limil }\end{array}$} \\
\hline $\begin{array}{l}\text { Center } \\
\text { (no channels) }\end{array}$ & 100 & 110 & 10 & - & - \\
\hline Outer channels & -29 & 97 & It & 330 & 48 \\
\hline \multirow[t]{2}{*}{ Midcile channels } & -29 & 90 & 13 & 310 & 15 \\
\hline & -42 & 90 & 13 & 310 & 31 \\
\hline \multirow[t]{2}{*}{ Inner channels } & $\sim 28$ & 130 & 19 & 170 & 08 \\
\hline & $\sim 21$ & 130 & 19 & .20 & 90 \\
\hline Average & & 1 to & 10 & & \\
\hline
\end{tabular}

TABLE 2. Flow stresse: of Glidcop coupons cut from a bonded 5c-cm-diam target.

\begin{tabular}{|c|c|c|c|c|c|}
\hline Prisition of coupon & $\begin{array}{l}\text { Solid arca } \\
\text { (\%) }\end{array}$ & \multicolumn{2}{|c|}{$\begin{array}{l}\text { Flow stress actoss coupon } \\
\text { at proportional limit }\end{array}$} & \multicolumn{2}{|c|}{$\begin{array}{l}\text { Stress in lunds at } \\
\text { proportional limit }\end{array}$} \\
\hline $\begin{array}{l}\text { Center } \\
\text { (no channels) }\end{array}$ & 100 & 220 & 32 & - & - \\
\hline Inner channels & -25 & 120 & 18 & 500 & 72 \\
\hline \multirow[t]{2}{*}{ Middle channels } & $\sim 29$ & 93 & 13.5 & 320 & 97 \\
\hline & -42 & 86 & 12.5 & 210 & 30 \\
\hline Outer channels & $\sim 30$ & 110 & 16 & 370 & 53 \\
\hline
\end{tabular}




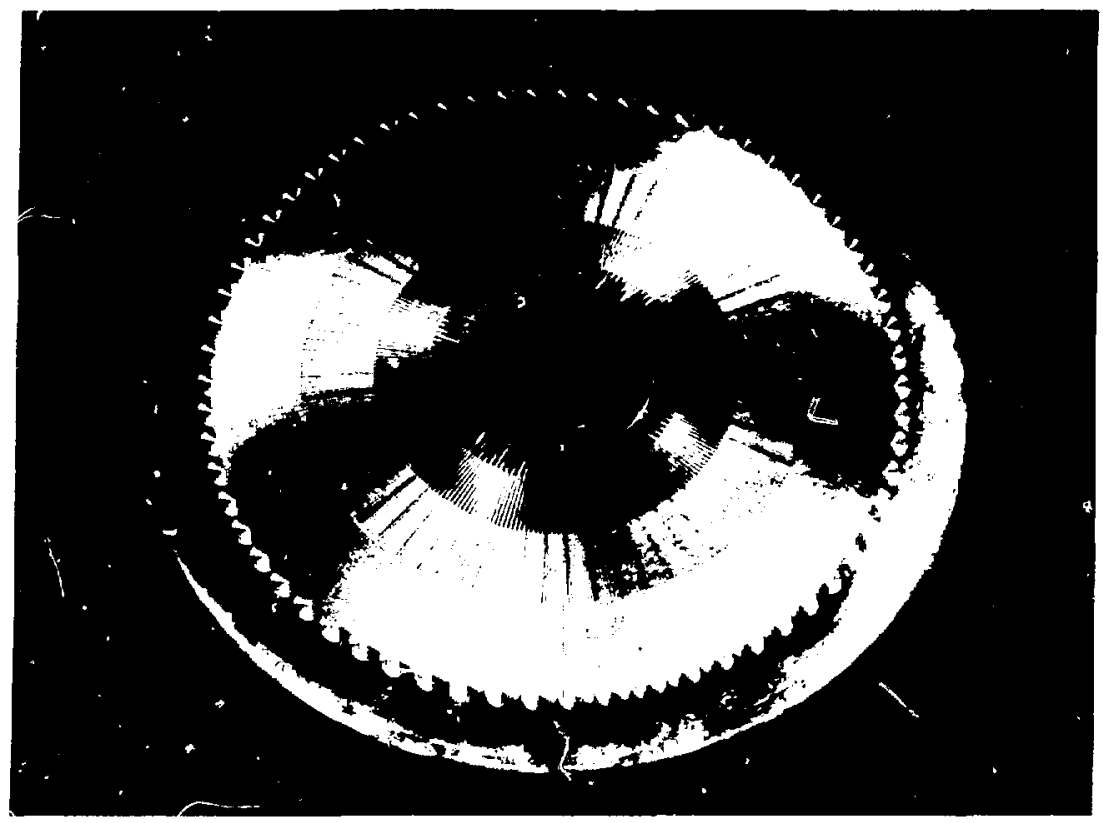

FIC. 2. RTNS-II 50-cm-diam target blank with cooling water channels etched into faying surface.

channels subdivide and become narrower. We measured the flow stress at the proportional limit for coupons from each of these areas, as ruell as for coupons cut from near the target center, which had no channels. The ratio of channel to land area depends on the actual position of the coupon in the target. We estimated the channel-to-land ratio for each coupon and used this ratio to calculate the compressive stress actually borne by the lands. Both the overall stresses and the stresses in the lands are given in Tables $I$ and 2.

The flow stress for Amzirc was fairly independent of position and ranged from 80 to $130 \mathrm{MPa}$ (12 to $19 \mathrm{ksi}$ ) for different areas of the target. As an average, we would expect that a stress of about 110 MPa ( $16 \mathrm{ksi}$ ) would be required to begin to crush the channels of an intact target at ambient temperature. The flow stress for Glidcop coupons taken from the inner and middle sections was 140 to $170 \mathrm{MPa}$ (21 to $25 \mathrm{ksi}$ ), but only $80 \mathrm{MPa}$ (12 ksi) for a coupon from the outer section. We do not understand why this outer section had a lower flow stress, but since we no longer use Glidcop for targets we did no further analysis.

Tables 1 and 2 also give the stress borne by the lands : ach coupon at the proportional limit. No explanation for the difference in values between various target lecations is obvious.

\section{Elevated Temperature Creep}

We measured the creep of Amzirc cijupons at elevated temperatures. These tests were at constant load, and also nearly at constant siress, since the coupon area grew little during testing. Each test was for $1 \mathrm{~h}$ at the following pressures and temperatures: $70 \mathrm{MPa}(10 \mathrm{ksi})$ at $350^{\circ} \mathrm{C}, 35,70$, and 


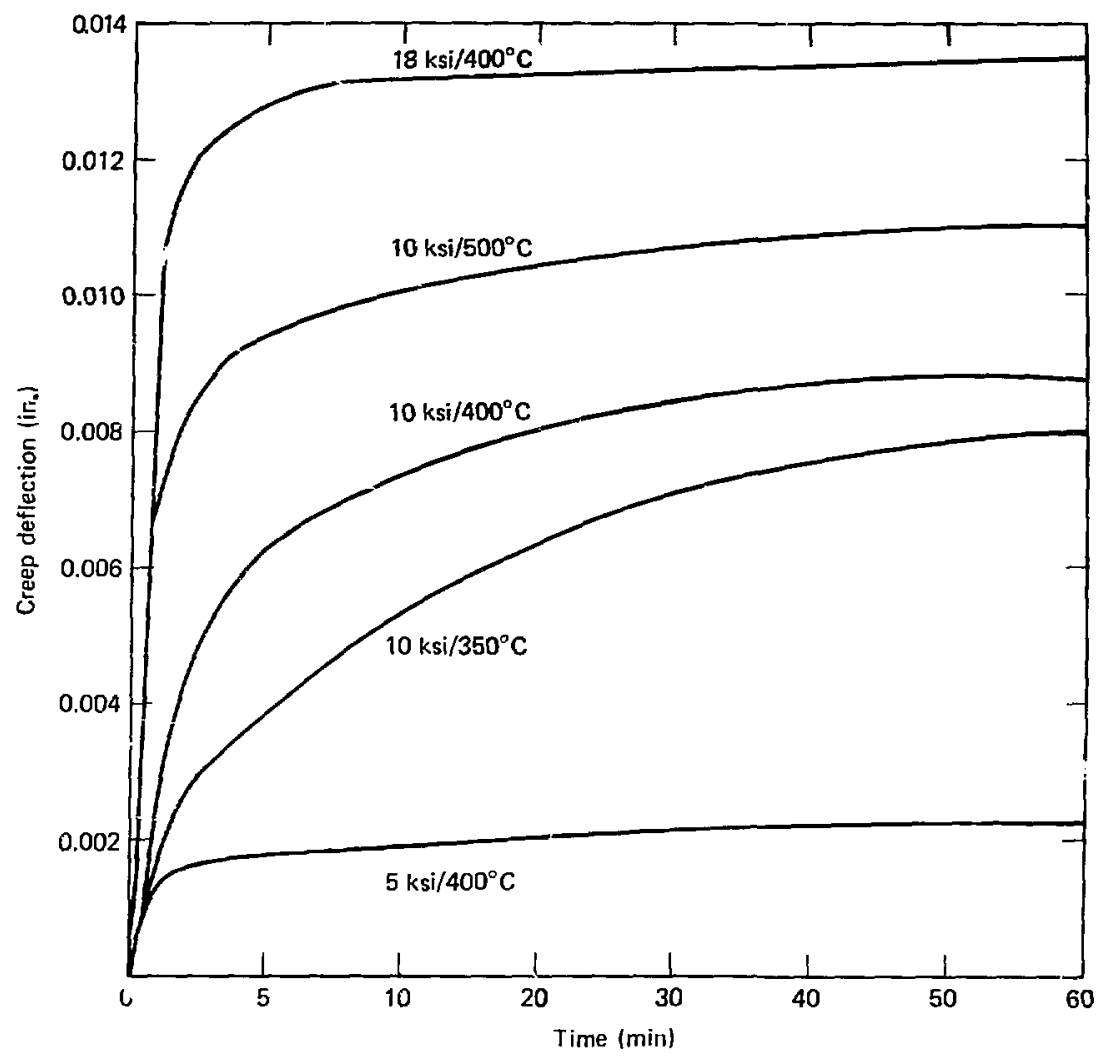

FIG. 3. Creep of 5/8-in.-diam coupons cut from a bonded Amzirc target and subjected to compressive loading.

$125 \mathrm{MPa}(5,10$, and $18 \mathrm{ksi})$ at $400^{\circ} \mathrm{C}$, and $35 \mathrm{MPa}$ $(5 \mathrm{ksi})$ at $500^{\circ} \mathrm{C}$. The creep curves for these coupons are shown in Fig. 3. The measured deflections are a sum of three contributions: (1) flattening of the curved surfaces, since the coupons were cut from a target having spherical curvature (60- $\mu \mathrm{m}$ max). (2) channel closure (15- $\mu \mathrm{m}$ max), and (3) thinning of the bonded plates by creep in a radial direction.
We could not separate these different contributions to the deflection from the creep curves. so we sectioned each coupon, photographed the channel openings, and estimated the amount of closure from the photomicrographs. Figure 4 is a surface view of a typical etched channel area, and Fig. 5 shows the cross sections of channels from two autoclave-bonded targets. These channels exhibit little discernible crushing, but it is apparent 


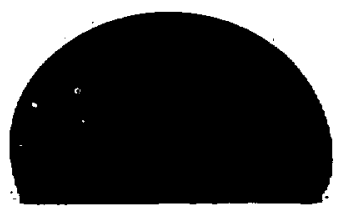

FIC. 4. Detail of etched channel pattern on bonded and delaminated RTNS-II target.

that the actual channel depth varies with the amou.at of etching, as well as its location in the target.

Figures o through io show the amount of channel closure for each tested coupon. Since heating was done in air, the dark layer that delineates the inside of the channels is copper axide. This layer proved useful for determining the original width of each channel, inasmuch as the channels were of varying widths since they come from different parts of the bonded target. The amount of channel area remaining open was measured on each photomicrograph, and the original channel area was calculated from its original width. (For this calculation, we assumed that the original cross-sectional area was a semicircle.) The percentage of the channel area remaining open after pressing is given in Table 3 and Fig. 11. The amount of crushi.ıg depended much more strongly on pressure than on temperature. If we estimate that $20 \%$ closure is the greatest that could be tolerated. the safe prassure limit appears to be $\mathbf{4 0}$ $\mathrm{MPa}\left(0 \mathrm{ksi}\right.$ ) for bonding at $450^{\circ} \mathrm{C}$, and about 55 $\mathrm{MPa}(8 \mathrm{ksi})$ for bonding at $300^{\circ} \mathrm{C}$. This limit may be conservative, as tests wele made on coupons which had been previously bonded and hence had undergone some annealing. Unannealed Amzirc would probably deforin somewhat less during bonding.

We used this information to calculate "safe" bonding parameters, i.e., those regimes of pressure and temp-rature in which bonding will occur with Jesa than $20^{\circ}$ channel closure. From Fig. 11 we esinmated tour pressure-temperature pairs, each of whtuct should result in about $20 \%$ channel closure.

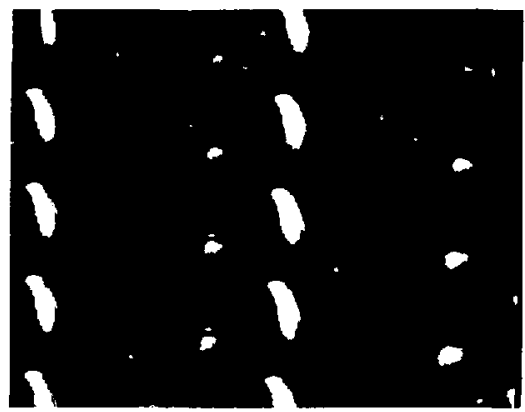

FIG. 5. Cross secition of autoclave-bonded RTNS-II target showing cooling channel as bonded (I0)x).

From these four pairs, we constructed the $20 \%$ channel closure curve shown in Fig. 12, using constant second differences to smooth the curve. Combinations of pressure and temperature above this line should result in more than $20 \%$ channel closure and those below this line in less than $20 \%$ closure.

We used data of Knowles ${ }^{2}$ to construct the silver-to-silver bonding curve also shown in Fig. 12. Pressure-temperature pairs ahove this curve should give bond strengths greater than $70 \mathrm{MPa}$ $(10 \mathrm{ksi})$. Knowles data are for bonding very clean silver surfaces at temperatures below $200^{\circ} \mathrm{C}$. Since our electroplated silver surfaces will get much handling and thus not be as clean, we extrapolated his

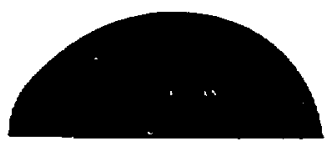

FIC.: Cross section of autoslave-bonded RTNS-Il target showing a cooling channel. Piessed for $I \mathrm{~h}$ at $35 \mathrm{MPa}$ (5 ksi) and $400^{\circ} \mathrm{C}$ after bonding. No detectable channel closure $(75 \times)$. 

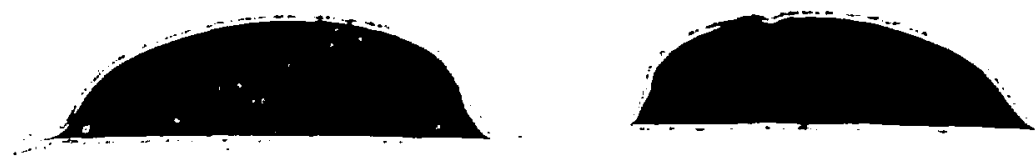

FIG. 7. Cross sections [(a) and (b)] of autoclave-bonded RTNS-II target showing a cooling channel. Pressed for $1 \mathrm{~h}$ at $70 \mathrm{MPa}(10 \mathrm{ksi})$ and $350^{\circ} \mathrm{C}$ after bonding. Channel cross section 29 to $30 \%$ of original area (100x).
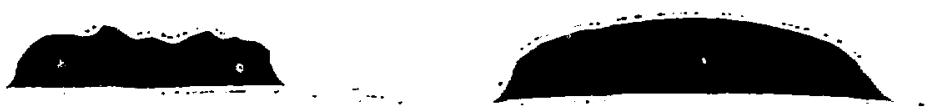

FIG. 8. Cross sections [(a) and (b)] of autoclave-bonded RTNS-I] target showing a cooling channel. Pressed for $\mathrm{I} \mathrm{h}$ at $70 \mathrm{MPa}(10 \mathrm{ksi})$ and $400^{\circ} \mathrm{C}$ after bonding. Channel cross section 10 to $2 \mathrm{I} \%$ of original area $(100 \times)$.
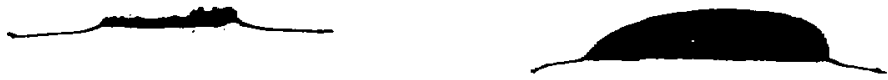

FIG. 9. Cross sections [(a) and (b)] of autoclave-bonded RTNS-II target showing a croling channel. Pressed for $1 \mathrm{~h}$ at $70 \mathrm{MPa}(10 \mathrm{ksi})$ and $500^{\circ} \mathrm{C}$ after bonding. Channel cross section 5 to $20 \%$ of original area $(75 \times)$. 
FIC. I0. Cross sections of autoclave-bonded RTNS-II target showing a cooling channel. Pressed for $1 \mathrm{~h}$ at $125 \mathrm{MPa}(18 \mathrm{ksi})$ and $400^{\circ} \mathrm{C}$ after bonding. Channel cross section 0 to $2 \%$ of original area (75 $\times$ ).

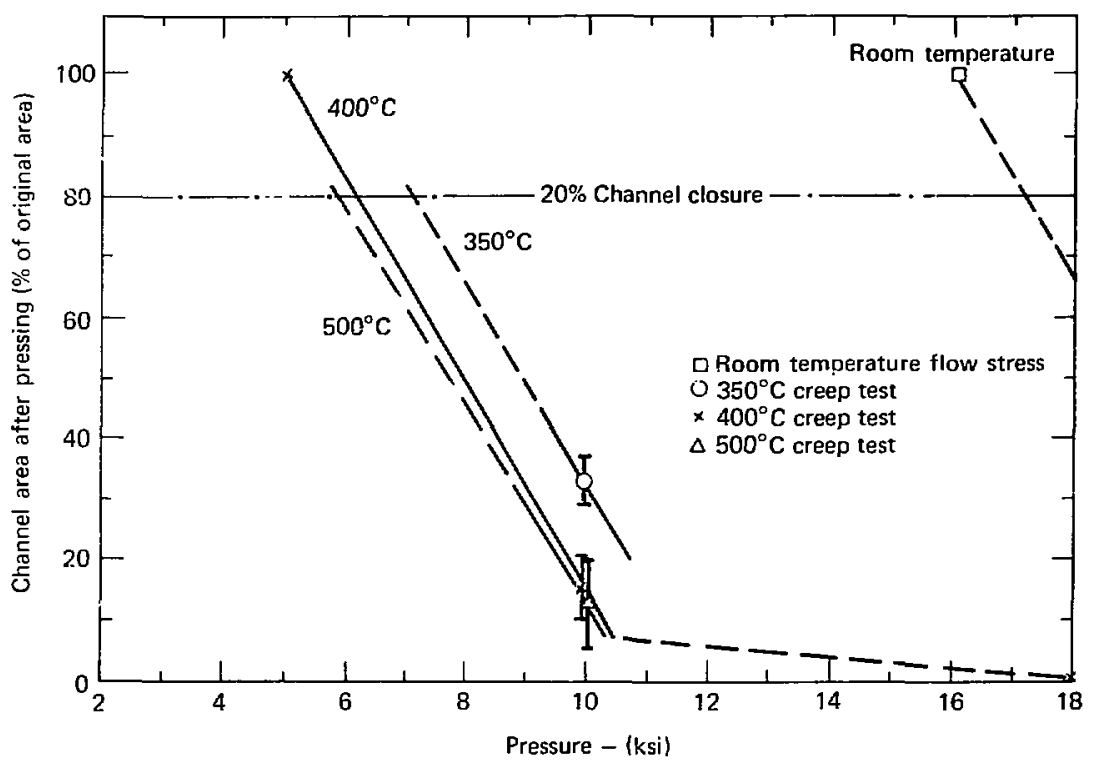

FIG. 11. The effect of pressure and temperature on channel closure in coupons cut from a bonded Amzirc target. 
TABLE 3. Channel area remaining open after pressing for $1 \mathrm{~h}$, expressed as a percentage at the original cross-sectional area.

\begin{tabular}{|c|c|c|c|}
\hline $\begin{array}{c}\text { Temperature } \\
\left({ }^{\circ} \mathrm{C}\right)\end{array}$ & $35 \mathrm{MPa}$ (5 ksi) & $\begin{array}{c}\text { Pressute } \\
\text { 70 MPa (10 ksi) }\end{array}$ & $125 \mathrm{MPa}$ (18 ksi) \\
\hline 350 & & 29 to $37 \%$ & \\
\hline 400 & $-100 \%$ & $101021 \%$ & 0 to $2 \%$ \\
\hline 500 & & 5 to $20 \%$ & \\
\hline
\end{tabular}

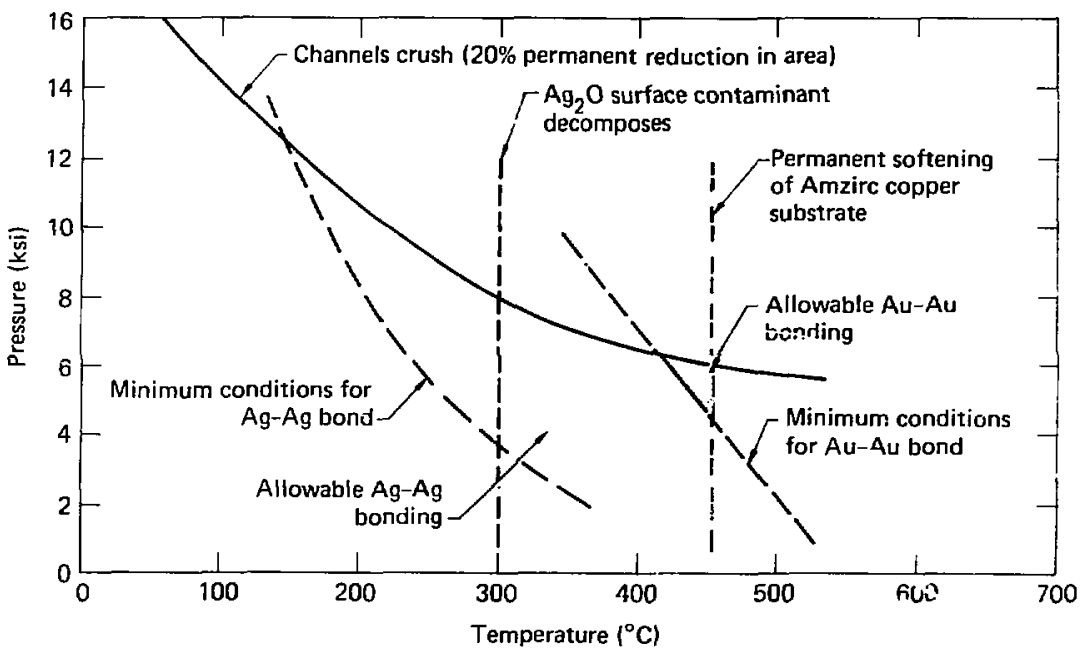

FIG. 12. Prediction of "safe" bonding parameters. Safe areas lie between the $20 \%$ channel closure line and either the $\mathrm{Ag}-\mathrm{Ag}$ bonding line or the $\mathrm{Au}-\mathrm{Au}$ bonding line.

data to above $300^{\circ} \mathrm{C}$, the decomposition temperature of $\mathrm{Ag}_{2} \mathrm{O}$. Above this temperature, silver dissclves its oxide and also scavenges many surface contaminants. The area for "safe" bonding of silver-plated targets is marked on Fig. 12.

Gold is much more difficult to bond than silver. ${ }^{3.4}$ While it does not form an oxide, neither does it dissolve surface contamination. Thus goldto-gold bonding parameters are higher than silverto-silver bonding parameters. We used a correlation by Bryant ${ }^{5}$ to estimate bonding parameters for gold using mechanical and elastic properties of the metal. The area for "safe" bonding of gold-plated targets is also shown on Fig. 12. 


\section{CONCI.USIONS}

The upper limits of pressure for autoclavebonding Amzirc target disks without crushing the cooling channels is 40 to $55 \mathrm{MPa}$ (6 to $8 \mathrm{ksi}$ ). These limits are relatively insensitive to temperature in the probable bonding temperature range of 300 to $450^{\circ} \mathrm{C}$. We expect that silver will bond at temFeratures above $300^{\circ} \mathrm{C}$ and gold will bond at temperatures above about $425^{\circ} \mathrm{C}$ when subjected to pressures near the channel crushing limit-

\section{REFERENCES}

1. W. D. Ludemann, G. A. Harter, and B. J. Schumacher, Analysis of Bond-Failures in RTNS-II Targets, Lawrence Livermore National Laboratory, Livermore, CA. UCRL-53184 (1981).

2. J. 1. Knowles, High-Strength, Low-Temperature Bonding of Beryllium and Other Metals, Lawience Livermore National Laboratory, Livermore, CA, LCRL-50766 (1970).

3. R. F. Tylecote, "Investigations on Pressure Welding." in Brit. Welding J. 1, 117-135 (1959).

4. J. L. Tellison, "Effect of Sirface Contamination on the Thermecompression Bondability of Gold," in IEEE Trans. on Parts, Hybrids, and Packaging, PHP-1 1(3) (Sept. 1975).

5. W. A. Byrant, "A MAthod of Specifying Hot Isoslatic Pressure Welding Parameters," in Welding Research Supplement 54, 433-435 (1975). 